\title{
CORRECTION
}

\section{Correction: External validation of risk prediction models for incident colorectal cancer using UK Biobank}

\author{
J. A. Usher-Smith, A. Harshfield, C. L. Saunders, S. J. Sharp, J. Emery, F. M. Walter, K. Muir and S. J. Griffin
}

British Journal of Cancer (2020) 122:1572-1575; https://doi.org/10.1038/s41416-020-0767-0

Correction to: British Journal of Cancer (2018) 118, 750-759; https:// doi.org/10.1038/bjc.2017.463, published online 30 January 2018.

Since the publication of this paper, the authors have identified an error in the code they used in Stata to compute the Wells risk score for men. With the correct code, the performance of the Wells risk score is improved. The correct values are included in the updated versions of Table 3, Fig. 1 (Fig. 1A), Fig. 2 (Fig. 2A) and Supplementary Table 3 provided here. The Wells risk score is now one of the best performing models in men as well as in women. This does not change the overall conclusions of the analysis but in all places in the paper where reference is made to the best performing models in men, the correct list is Tao, Drive, Ma and Wells. (c) Open Access This article is licensed under a Creative Commons Attribution 4.0 International License, which permits use, sharing, adaptation, distribution and reproduction in any medium or format, as long as you give appropriate credit to the original author(s) and the source, provide a link to the Creative Commons licence, and indicate if changes were made. The images or other third party material in this article are included in the article's Creative Commons licence, unless indicated otherwise in a credit line to the material. If material is not included in the article's Creative Commons licence and your intended use is not permitted by statutory regulation or exceeds the permitted use, you will need to obtain permission directly from the copyright holder. To view a copy of this licence, visit http://creativecommons. org/licenses/by/4.0/.

(c) The Author(s) 2020 


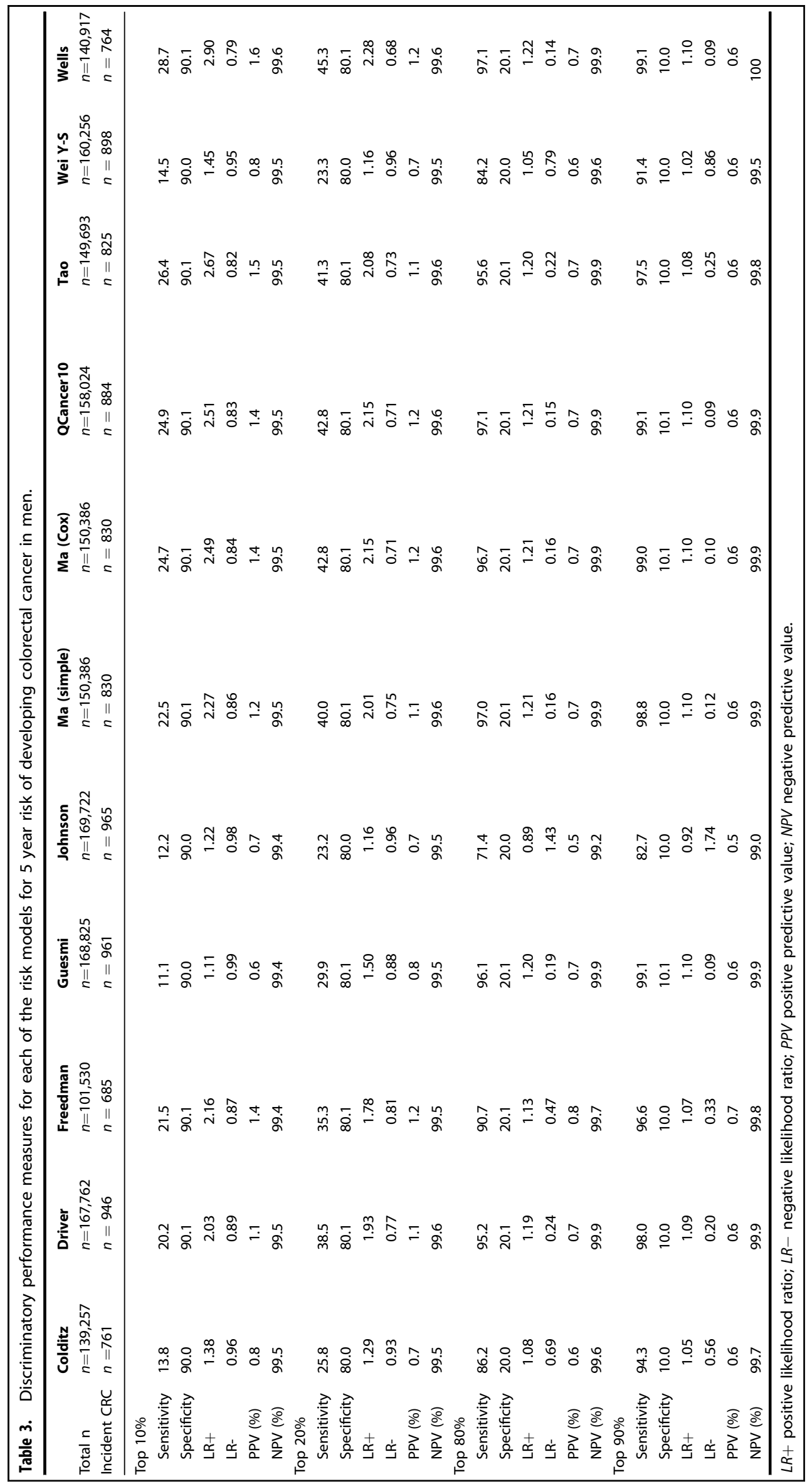


Correction: External validation of risk prediction models for incident...

JA Usher-Smith et al.

1574

A

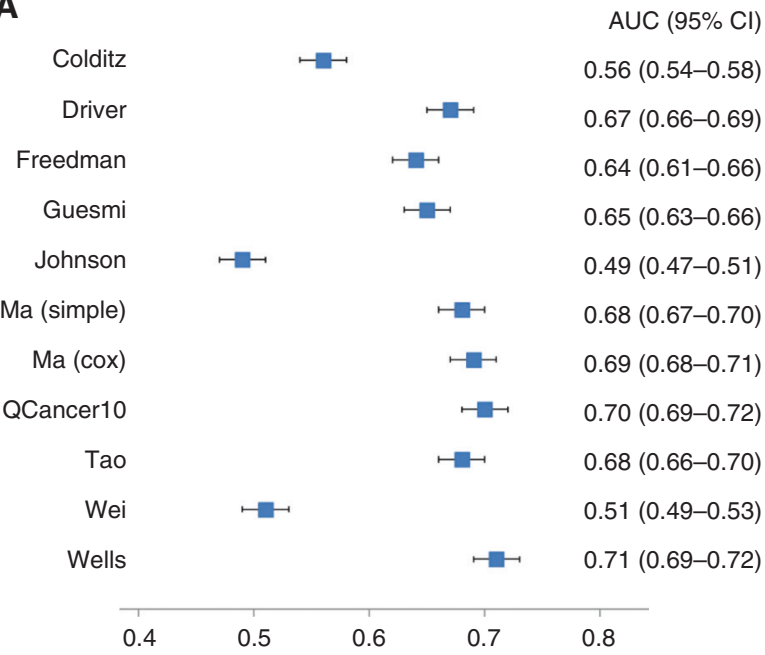

Area under the receiver operating characteristic curve (AUC)
$\mathbf{B}$

$\operatorname{AUC}(95 \% \mathrm{Cl})$

\begin{tabular}{|c|c|c|c|}
\hline Colditz & - & & $0.50(0.48-0.53)$ \\
\hline Freedman & & $\mapsto$ & $0.59(0.56-0.61)$ \\
\hline Guesmi & & $\bullet$ & $0.63(0.62-0.64)$ \\
\hline Johnson & 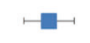 & & $0.50(0.48-0.52)$ \\
\hline QCancer10 & & 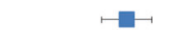 & $0.66(0.64-0.68)$ \\
\hline Tao & & - & $0.64(0.62-0.66)$ \\
\hline Wei & $\mapsto$ & & $0.49(0.47-0.51)$ \\
\hline Wells & & 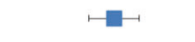 & $0.65(0.63-0.67)$ \\
\hline Driver* & & $\vdash$ & $0.63(0.61-0.65)$ \\
\hline Ma (simple)* & & $\because$ & $0.64(0.62-0.66)$ \\
\hline $\mathrm{Ma}(\operatorname{cox})^{\star}$ & & $\square$ & $0.64(0.62-0.66)$ \\
\hline 0.4 & 0.5 & 0.6 & 0.8 \\
\hline
\end{tabular}

Area under the receiver operating characteristic curve (AUC)

Fig. 1 Model discrimination. Area under the receiver operating characteristic curve for the risk models in (A) men and (B) women. ${ }^{*}$ Models originally only developed in men. 

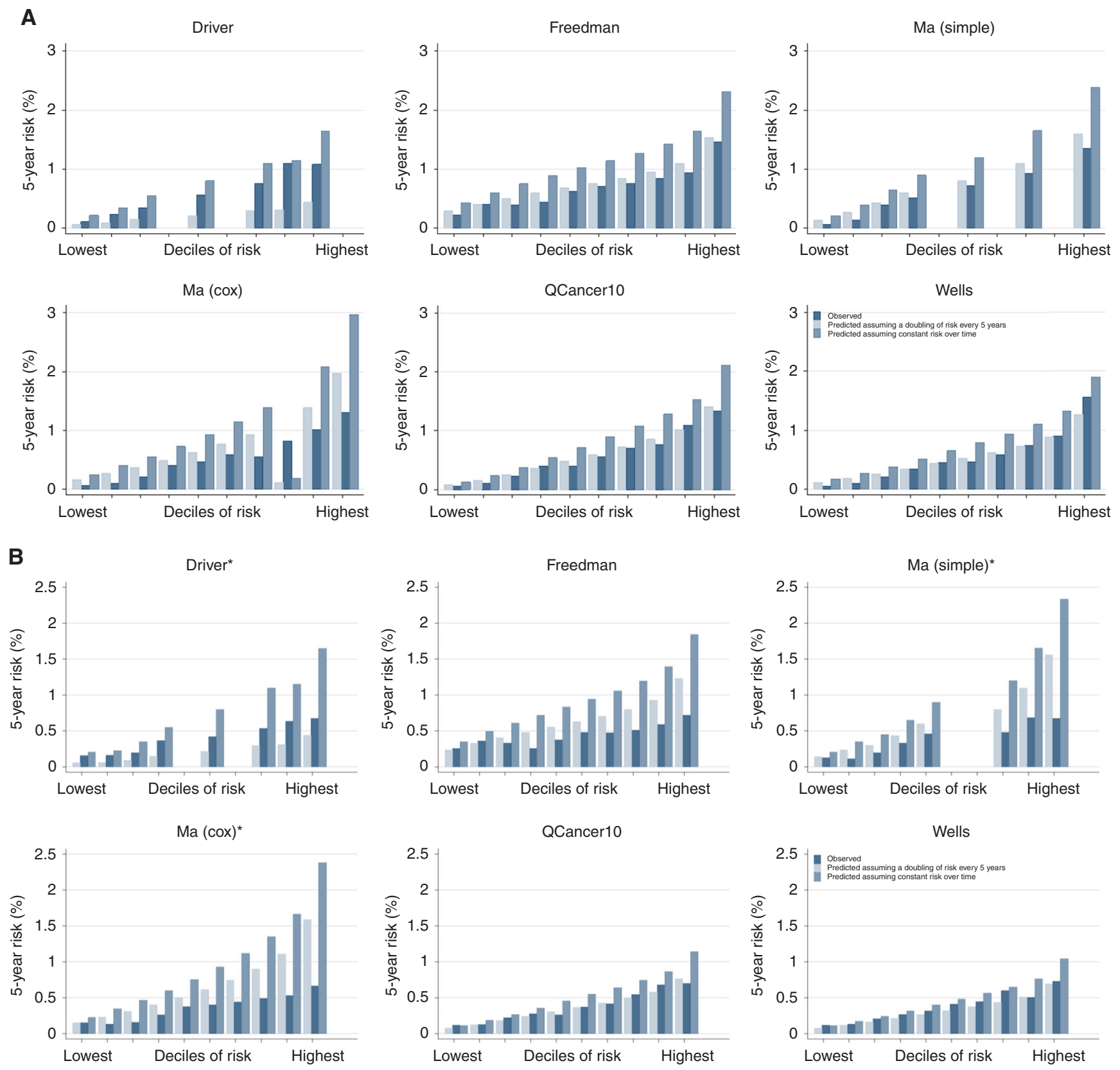

Fig. 2 Model calibration. Plots of observed and predicted 5-year risk of colorectal cancer for (A) men and (B) women. * Models originally only developed in men. 